\title{
Pesquisa e inovação responsáveis: conceituação, surgimento e desafios para implementação
}

\author{
Maria Zanin \\ Doutora; Universidade Federal de São Carlos, São Carlos, SP, Brasil \\ mariazanin55@gmail.com; ORCID: http://orcid.org/0000-0002-5757-2910 \\ Adriana Gonçalves Arruda \\ Doutora; Universidade Federal de São Carlos, São Carlos, SP, Brasil \\ E-mail: adrianaarruda@ufscar.br; ORCID: http://orcid.org/0000-0001-5779-6714 \\ Danilo Rothberg \\ Doutor; Universidade Estadual Paulista Júlio de Mesquita Filho, Bauru, SP, Brasil \\ danroth@uol.com.br; ORCID: https://orcid.org/0000-0002-3103-8154
}

Resumo: Atualmente, há uma demanda para se produzir ciência de forma participativa, já que agentes da sociedade - pesquisadores, legisladores, políticos, educadores, empreendedores e cidadãos - deveriam se engajar no processo da produção científica (desde a construção da agenda até a concretização do projeto e resultados) com o intuito de fomentar a construção de uma sociedade responsável com o futuro. Os desafios deste contexto têm sido objeto de abordagens teóricas de Responsible Research and Innovation (traduzido por Pesquisa e Inovação Responsáveis), que este artigo descreve, examina e contextualiza no cenário atual. A metodologia engloba revisões bibliométrica e bibliográfica, utilizadas a fim de facilitar a compreensão da disseminação do conceito nas línguas inglesa e portuguesa (Brasil), além de resgatar o contexto da PIR, explorar suas conceituações e princípios. Buscou-se refletir sobre os desafios da implementação da PIR no Brasil. Espera-se contribuir para o diálogo da PIR no País e suscitar reflexões sobre a importância de aplicá-la para fortalecer agentes e iniciativas responsáveis nos âmbitos socioeconômico e ambiental.

Palavras-chave: Pesquisa e Inovação Responsáveis; Engajamento Público da Ciência; Ciência, Tecnologia e Inovação; Ciência, Tecnologia e Sociedade; Políticas Públicas.

\section{Introdução}

A influência da sociedade em geral sobre a delimitação de prioridades de programas de pesquisa é um dos temas mais prementes da contemporaneidade, quando a escassez de recursos financeiros exige que a ciência esteja continuamente disposta a demonstrar seu valor. $\mathrm{O}$ relacionamento entre os 
cientistas e os diversos setores sociais tende a ocorrer, de forma explícita ou não, conforme determinados propósitos, nem sempre com a abertura devida.

Em geral, a inovação tende a estar mais facilmente dependente das demandas industriais, já que surge no contexto de programas nos quais o diálogo é institucionalmente requerido. Mas nem sempre há essa proximidade nas diversas áreas do conhecimento, problema que tem recebido variadas respostas. No âmbito da União Europeia, os requisitos do que se convencionou chamar de PIR (Pesquisa e Inovação Responsáveis) foram enfatizados pelo programa continental de pesquisa denominado Horizon 2020, que traz o imperativo de abrir, sistematicamente, canais permanentes de escuta da sociedade para a formulação de prioridades de pesquisa. No âmbito do Horizon 2020, foi criado, também, o Higher Education Institutions and Responsible Research and Innovation (Heirri), um programa voltado especificamente para instituições de Ensino Superior pelo mundo, a fim de incentivar a integração de pesquisa e inovação com demandas da sociedade, também com o respaldo dos conceitoschave da PIR.

Reflexões decorrentes desse contexto se desenvolvem em torno de pensar quais são os parâmetros e diretrizes capazes de tornar a atividade científica disposta a incentivar o engajamento público nas esferas decisórias da produção da ciência. Além disso, torna-se necessário indagar quais são as estratégias necessárias para que, após o incentivo adequado à participação da sociedade na definição de prioridades de pesquisa, os cientistas possam prestar contas à sociedade sobre o que produziram com recursos públicos.

Este artigo oferece uma contribuição à elaboração destas reflexões, ao caracterizar conceitos, origens e desafios das iniciativas de Pesquisa e Inovação Responsáveis nas intersecções possíveis entre as trajetórias da União Europeia e do Brasil.

Partindo da premissa de que o conceito de PIR é pouco difundido no Brasil, este artigo examina suas diferentes abordagens teóricas, definidas por diversos autores. Para isso, utilizou, como metodologias, i) uma breve revisão bibliométrica, que apontou escassez na quantidade de publicações acadêmicas da temática na língua portuguesa; e ii) revisão bibliográfica sobre o conceito. 
Tomou-se, como ponto de partida da revisão bibliográfica sobre o tema, o próprio site oficial RRI-Practice (2016), que define a Inovação e Pesquisa Responsável no contexto da União Europeia. A revisão também rastreia exemplos sobre a prática nos sites RRI Tools (2021), Heirri (2015) e bases de dados que citam as iniciativas Horizon 2020, Heirri e o termo PIR, além de abranger textos institucionais e científicos relacionados à temática. O objetivo é resgatar o contexto histórico do conceito, explorar suas bases e seus seis princípios - governança, educação científica, ética, igualdade de gênero, acesso aberto aos resultados de trabalho científico e engajamento público da ciência - e a relação deles com suas quatro diretrizes - antecipação, reflexividade, inclusão e responsividade.

Por fim, com base nessas conceituações, buscou-se debater brevemente os possíveis desafios de sua aplicação no Brasil, com o breve exemplo da aplicação realizada em um projeto conjunto entre a Universidade Estadual de Campinas (Unicamp) e a Fundação de Amparo à Pesquisa do Estado de São Paulo (FAPESP). São também examinadas, brevemente, as etapas de elaboração participativa do programa Horizon Europe, sucessor do Horizon 2020, que deve ser iniciado em 2021.

Espera-se, com este trabalho, contribuir para o diálogo e a disseminação da Pesquisa e Inovação Responsáveis no País e suscitar reflexões sobre a importância de aplicá-la para existirem, a longo prazo, agentes - pesquisadores, políticos, cidadãos - e, consequentemente, iniciativas conscientes e responsáveis que projetem a relevância da pesquisa e inovação nos âmbitos socioeconômico e ambiental.

\section{Pesquisa e Inovação Responsáveis: breve revisão bibliométrica, conceitos e caracterização}

A revisão bibliométrica envolveu buscas realizadas em bases de dados acadêmicas, no período de 2010 a 2021, comparando os resultados do termo em português e em inglês. A intenção, no entanto, não foi realizar uma pesquisa bibliométrica extensa e sistemática sobre o termo (sugestão, inclusive, para trabalhos futuros), tendo em vista que se trata de um artigo descritivo, que traz 
uma contribuição sobre os fundamentos da PIR, mas sim destacar um breve panorama sobre a quantidade de publicações acadêmicas neste escopo, no sentido de apontar tendências e evoluções na temática.

Considerou-se, nesse momento, variações dos termos, como alternância de ordem e alteração de pronomes. Foi constatado que há, ainda, pequena quantidade de pesquisas no Brasil sobre PIR. Os resultados dos termos em inglês são muito mais expressivos, conforme a Tabela 1 .

Tabela 1 - Número de publicações sobre PIR em bases de dados - 2010 a 2011.

\begin{tabular}{|c|c|c|c|c|}
\hline $\begin{array}{c}\text { Base de dado } \\
\text { Termo pesquisado }\end{array}$ & $\begin{array}{c}\text { Google } \\
\text { Acadêmico }\end{array}$ & $\begin{array}{c}\text { Portal de } \\
\text { Periódicos Capes }\end{array}$ & SciELO & $\begin{array}{c}\text { Biblioteca Digital } \\
\text { Brasileira de Teses } \\
\text { e Dissertações }\end{array}$ \\
\hline $\begin{array}{l}\text { "Pesquisa e Inovação } \\
\text { Responsáveis" }\end{array}$ & 87 & 6 & 1 & 1 \\
\hline $\begin{array}{l}\text { "Pesquisa e Inovação } \\
\text { Responsável" }\end{array}$ & 36 & 1 & 1 & 1 \\
\hline $\begin{array}{l}\text { "Inovação e Pesquisa } \\
\text { Responsável" }\end{array}$ & 6 & 0 & 0 & 0 \\
\hline $\begin{array}{l}\text { "Responsible Research } \\
\text { and Innovation" }\end{array}$ & 9.940 & 535 & 6 & 1 \\
\hline $\begin{array}{l}\text { "Responsible Innovation } \\
\text { and Research" }\end{array}$ & 41 & 1 & 0 & 0 \\
\hline
\end{tabular}

Fonte: Elaborada pelos autores.

Foram feitas buscas dessas expressões sem aspas, mas os resultados foram muito genéricos e pouco se relacionam com o escopo utilizado no artigo. A maioria da literatura utilizada nesta tese é internacional, com textos na língua inglesa, na qual foi encontrada uma maior quantidade de publicações acadêmicas.

Mas, afinal, qual é a origem do conceito de PIR? Até a década de 1960, a ciência ocasionou uma espécie de sentimento otimista perante os pesquisadores, as instituições e a própria sociedade por ter trazido importantes descobertas tecnológicas. No entanto, a partir deste período, vieram à tona as reflexões sobre possíveis consequências e efeitos imprevistos, a longo prazo, sobretudo à natureza, do uso dessa ciência, com o fomento de uma visão mais crítica sobre a temática.

Nesse contexto, há cerca de 60 anos, a própria sociedade constatou que pesquisa e inovação não eram necessariamente uma combinação de fatores positivos e nem sempre traziam sustentabilidade ao ambiente, bem-estar às 
pessoas e lucro para as instituições, ideia antes defendida, sobretudo por intelectuais.

O modelo de 'divisão do trabalho' em que as universidades pesquisam, as empresas inovam e os cidadãos e os consumidores se beneficiam automaticamente passou a ser criticado e questionado por diversos grupos, desde pesquisadores até a sociedade civil. (POSTAL; RIBEIRO; BENATI, 2019, p.8).

Macnaghten e Sykes (2013) atentam a quatro pontos que fortaleceram esta visão. Um deles diz respeito aos protestos realizados a partir da década de 1960, relacionados a projetos e visões tecnológicas, que reivindicavam responsabilidade ambiental. O outro envolve uma cobrança para que o próprio governo esteja engajado em iniciativas que envolvam ciência e tecnologia (C\&T), para que consiga controlar, de forma institucional, seus impactos e consequências. Também a partir desta época, surge uma maior necessidade de se ampliar os espaços para debates e participação social, para que as pessoas estejam cientes do que está acontecendo e consigam dar a sua opinião em prol de uma ciência mais sustentável. Por fim, outro ponto importante que levou a uma maior reflexão sobre a responsabilidade da ciência veio de uma demanda da própria comunidade científica, que sentiu a necessidade de tornar a ciência mais acessível e compreendida, aperfeiçoando a comunicação entre cientistapúblico (MACNAGHTEN; SYKES, 2013; POSTAL; RIBEIRO; BENATI, 2019).

É com este olhar mais crítico que surge a preocupação por pesquisa e inovação mais atenta, responsável, e, com ela, debates que visem não só a ética e as consequências de uma pesquisa, mas sim a participação e o engajamento públicos (POSTAL; RIBEIRO; BENATI, 2019). Neste cenário, um dos conceitos difundidos na União Europeia por meio do programa Horizon 2020 (EUROPEAN COMISSION, 2020a), e ainda incipiente no Brasil, é o de Responsible Research and Innovation (RRI), traduzido por Pesquisa e Inovação Responsáveis (PIR) neste artigo.

Ao passo que o programa Horizon 2020 adotou formas de avaliação de projetos de pesquisa priorizando aqueles que propuseram práticas de envolvimento da sociedade baseadas nos princípios descritos adiante, o programa sucessor, denominado Horizon Europe, em elaboração iniciada em 
2019, com vigência programada de 2021 a 2027, mantém e busca ampliar a participação social desde o processo de sua concepção. Sua estratégia incluiu situar a participação na própria formulação de suas diretrizes, por meio de consultas públicas e 20 eventos nacionais ou transnacionais, além de eventos centrais demarcando o processo nos anos de 2019 e 2020 (EUROPEAN COMISSION, 2020b).

Uma consulta pública se tornou peça da elaboração compartilhada da política pública de ciência e tecnologia no caso do Horizon Europe. A consulta foi desenvolvida como um percurso accountable (responsivo), buscando a maximização das oportunidades por meios das quais as contribuições pudessem ser apresentadas. Foram enviadas 1549 respostas, de 64 países, que convergiram ao apontar a importância de: simplificar o processo de submissão de projetos, com o objetivo de proporcionar isonomia no tratamento dos diversos agentes que competem por recursos financeiros (evitando, assim, a discriminação contra equipes de pesquisa com menos recursos humanos disponíveis para a elaboração de propostas); tornar mais transparente o processo de avaliação de projetos, incluindo a visibilidade dos critérios de seleção dos avaliadores; fornecer suporte constante aos proponentes de projetos e também aos projetos selecionados durante todo o percurso de seu desenvolvimento (EUROPEAN COMISSION, 2020b).

A construção do programa de pesquisa a viger até 2027 está lastreada na história de uma década. O termo PIR ganhou notoriedade em meados de 2010, segundo a Comissão Europeia (EUROPEAN COMISSION, 2020b), trazendo um olhar mais crítico e atento à importância de se produzir uma ciência mais responsável, colaborativa e sustentável. Neste contexto, em 2011, a Comissão Europeia criou uma proposta para definir e caracterizar este termo, entendendoo como um conjunto de atores que trabalham juntos ao longo de todo o processo que envolva pesquisa e inovação, no sentido de alinhar todos os passos e seus resultados, de acordo com valores éticos, interesses e expectativas da sociedade europeia.

Ela definiu, para organizações que, de alguma forma, envolvam ciência, tecnologia e inovação (CT\&I), que suas responsabilidades devam ir além do 
cumprimento de regras e regulamentos já preestabelecidos, fazendo com que alcancem uma abordagem integral de suas ações. Ou seja, ao inovar, já ao longo do processo, elas precisam entender que é necessário criar e compartilhar valores não somente a um público ou a um setor específico, mas sim com seus diversos agentes e a própria sociedade, identificando, antes mesmo de uma nova criação, um possível impacto desta inovação que possa prejudicar o mundo de alguma maneira. "A questão central em Pesquisa e Inovação Responsáveis é como melhor associar a inovação à responsabilidade para torná-la mais antecipatória" (SCHOLTEN et al., 2016, p.2-3, tradução nossa).

Segundo Von Schomberg (2011), trata-se de

Um processo transparente e interativo pelo qual os atores e inovadores da sociedade se tornam mutuamente responsivos uns aos outros com vistas à aceitabilidade (ética), sustentabilidade e desejabilidade social do processo de inovação e seus produtos comercializáveis. (VON SCHOMBERG, 2011, p. 9, tradução nossa).

O programa Horizon 2020 sustenta a exigência de envolvimento de diversos atores sociais - como pesquisadores, cidadãos, formuladores de políticas, empresas, organizações do terceiro setor -, "que trabalham juntos durante todo o processo de pesquisa e inovação para alinhar melhor o processo e seus resultados aos valores, necessidades e expectativas da sociedade" (EUROPEAN COMISSION, 2020a, tradução nossa). Ou seja, não se trata simplesmente de promover uma pesquisa responsável em um sentido amplo, no qual apenas documentos informativos relatem o que foi feito ou somente os resultados, mas sim antecipar possíveis riscos e benefícios, ainda em fases de pesquisas de determinada inovação e, principalmente, delimitar quem e o que esta tecnologia impactará - positiva ou negativamente - ao se tornar, efetivamente, uma inovação.

Nesse sentido, o conceito de PIR, defendido pelo Horizon 2020, reforça a pertinência de se produzir pesquisa e inovação com pensamento a longo prazo, desmistificando a ideia de que elas são sempre vistas como acontecimentos positivos e essenciais para a sociedade em detrimento de importantes fatores, como impactos sociais, econômicos e ambientais. Tem-se, portanto, o fomento a um olhar crítico, reflexivo e abrangente, em que uma só resposta não é 
suficiente. A PIR visa o entendimento da ciência de uma maneira global, com questionamentos: quem se beneficia? De quais maneiras? Prejudica algo ou alguém? Quais impactos a curto, médio e longo prazos que a ciência trará não somente ao homem, mas também à natureza, à economia, à política e demais áreas? Quais áreas de conhecimento da PIR têm interface? A compreensão desse termo envolve outras áreas do conhecimento? Tem-se o olhar do todo e, ao mesmo tempo, de fragmentos, de cada agente envolvido, direta ou indiretamente, englobando o conceito de transdisciplinaridade, que vai além da aproximação de disciplinas e áreas do conhecimento e traz como principal objetivo a compreensão do mundo presente, passando entre, através e além das disciplinas com o intuito de se ampliar o conhecimento (NICOLESCU, 1999).

Para Hartley, Pearce e Taylor (2017), o conceito de PIR se configura como um convite a uma nova visão de sociedade, igualitária e inclusiva, promovendo reflexões sobre novos caminhos para que o público participe da formulação de decisões sobre políticas científicas e monitore seus resultados. É neste cenário que a PIR é uma ferramenta para auxiliar a renovação entre contatos e ligações entre decisores políticos e os demais públicos (HARTLEY; PEARCE; TAYLOR, 2017).

A PIR indica que, quando fundos públicos são investidos em inovação, por exemplo, é preciso esclarecer qual o resultado daquele tipo de inovação e quem ela beneficia (SCHOLTEN et al., 2016). O conceito situa a sociedade como participante de processos científicos, e não apenas como possível beneficiada. Em síntese, pode-se definir ao RRI três grandes áreas: a primeira que envolve a sociedade em ciência e inovação, a segunda é a conexão de diferentes aspectos entre RRI e a sociedade, e o último é a questão transversal a ser promovida no Horizon 2020", indica KOWALSKI (2018, p. 66, grifo nosso), que sublinha a necessidade de compartilhamento da responsabilidade entre os diversos setores sociais que financiam e podem se beneficiar da pesquisa.

Com estas características, a PIR leva o conhecimento para além dos muros de universidades e instituições de ensino e pesquisa. Seu propósito é tornar seus agentes mais conscientes dos novos desafios, problemas e questões 
sociais, construindo uma sociedade crítica e responsável com o mundo que deseja habitar (ANGELAKI, 2016; TORRES; KOWALSKI; SANTOS, 2018).

Neste cenário, em 2014, a Comissão Europeia determinou seis princípios da PIR que visam trazer o seu propósito à prática. São eles:

a) governança, que se relaciona aos métodos de produção, interpretação, uso e comunicação do trabalho científico, por meio da construção de arranjos institucionais que sejam fortes e que se adaptem ao desenvolvimento de pesquisa e inovação. Este princípio atenta para a prestação de contas entre os atores envolvidos na pesquisa e auxílio para promover responsabilidade compartilhada;

b) educação científica, que visa conscientizar jovens, já no âmbito educacional, sobre a importância de se produzir pesquisa e inovação responsáveis, preparando assim a sociedade desde cedo com os conhecimentos necessários sobre a temática para que, inclusive, possa incentivar o aumento do número de pesquisadores;

c) ética, que se propõe a fortalecer a importância de produzir ciência de modo íntegro e que previna práticas de pesquisa inaceitáveis;

d) igualdade de gênero, que defende uma ciência mais igualitária e participativa, sobretudo fomentando o engajamento;

e) acesso aberto aos resultados de trabalho científico, que possibilita a disseminação do conhecimento científico, por meio de publicações, entrevistas e divulgação sem barreiras financeiras;

f) engajamento público na ciência, que visa envolver múltiplos atores pesquisadores, políticos, empreendedores, cidadãos - em todo o processo de pesquisa e inovação, alinhando os resultados obtidos aos reais valores, necessidades e expectativas.

Estas orientações buscam "gerar conscientização e ética responsável nas pesquisas e empreendimentos em inovação de forma que os projetos sejam sustentáveis e socialmente desejáveis" e "obter aprendizados a partir do engajamento de vários atores e instituições", indicam Postal, Ribeiro e Benati (2019, p. 10). 
Para facilitar a aplicação e o cumprimento dos seis preceitos defendidos pela PIR, foram criadas dimensões no âmbito da União Europeia, que surgiram justamente em debates relacionados à $\mathrm{C} \& \mathrm{~T}$ e que demonstraram a real demanda dos participantes para que se consiga atingir o propósito da PIR. Ainda assim, as dimensões estão em constante construção, tendo em vista que foram criadas muito recentemente e que o tema ainda está emergindo neste momento.

“As reflexões sobre a inovação e pesquisa responsável estão levando a novas discussões sobre a missão, o papel, a divisão do trabalho e como os programas transdisciplinares de ciência e inovação devem ser configurados" (POSTAL; RIBEIRO; BENATI, 2019, p.10). São quatro as dimensões, conforme explicam Stilgoe, Owen e Macnaghten (2013):

a) antecipação, que tem o intuito de antecipar possíveis consequências, a longo prazo, de pesquisas e inovações. Diferente de prever, a dimensão fomenta um estudo minucioso de inovações para entender possíveis danos e/ou benefícios que determinada tecnologia pode ocasionar ao planeta, pensando em alternativas que causem menor impacto ambiental.

b) reflexividade, visando fomentar ampla reflexão também dos impactos de inovações que estão sendo criadas e que vão além de uma só área de pesquisa.

c) inclusão, com o intuito de indicar como as partes interessadas podem participar do processo de pesquisa, com um método ativo em eventos abertos à comunidade. Essa inclusão fomenta engajamento público, respostas a novas perguntas e problemas de pesquisa e, consequentemente, criação de novos conhecimentos.

d) responsividade, que busca refletir, de um modo amplo, sobre se as pesquisas estão sendo desenvolvidas de modo responsável e se respondem a uma demanda social, de acordo com valores públicos. É uma capacidade de resposta, que gera novos conhecimentos, perguntas, dúvidas, respostas, e assim sucessivamente.

A partir dessas orientações e dos princípios mencionados, é possível identificar uma sinergia entre os conceitos expostos, sendo algumas orientações 
Pesquisa e inovação responsáveis: conceituação, surgimento e desafios para implementação Maria Zanin, Adriana Gonçalves Arruda, Danilo Rothberg

relacionadas a determinados princípios, que se mostram interligados, conforme sugere a Figura 1. 
Figura 1 - Dimensões e princípios direcionadores da Pesquisa e Inovação Responsáveis

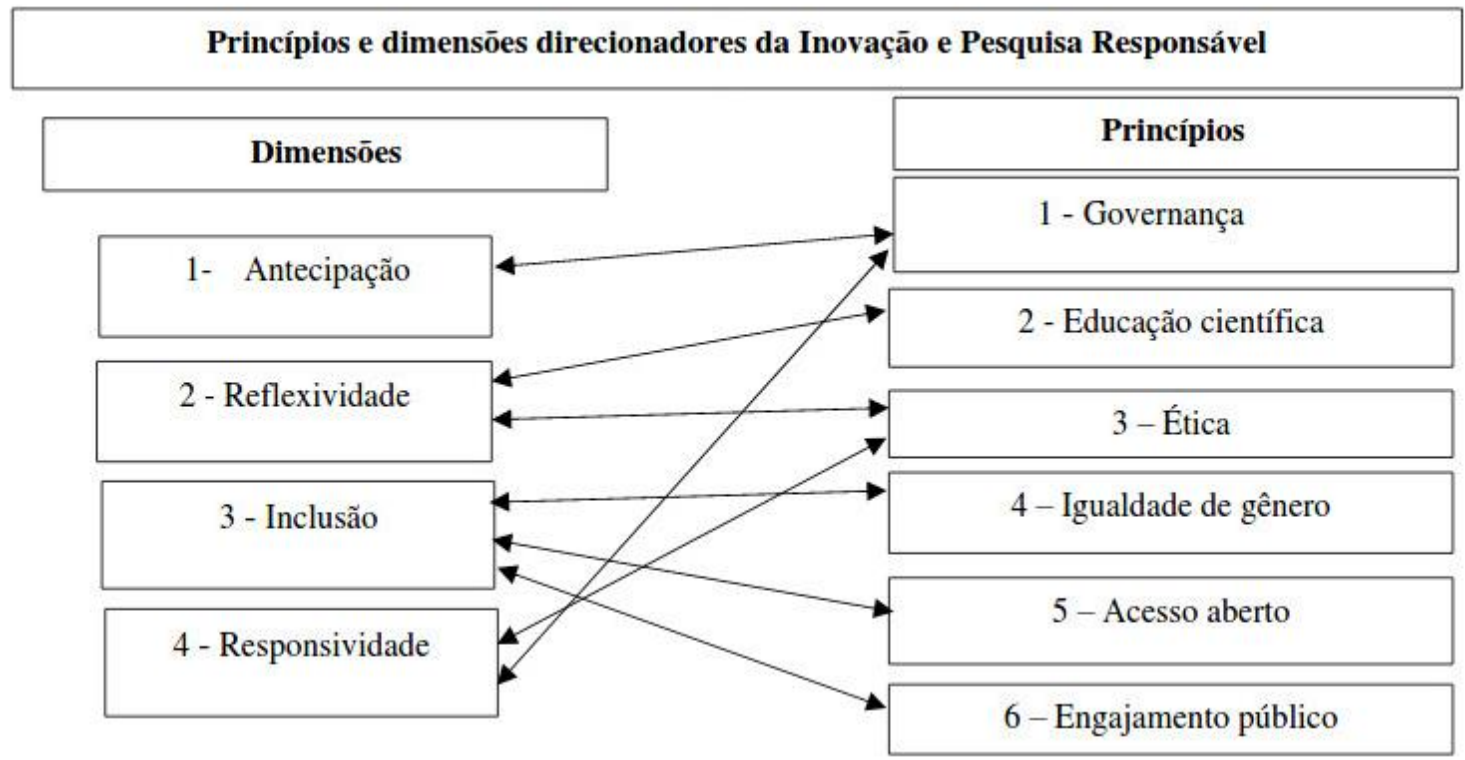

Fonte: Elaborado pelos autores.

Nesse sentido, ao buscarem praticar as quatro orientações e, dessa forma, atingir os princípios da PIR, os agentes participativos tentarão caminhos e soluções que irão minimizar possíveis consequências negativas da pesquisa e inovação.

Uma das iniciativas práticas impulsionadas pelo Horizon 2020 e voltada mais especificamente ao ensino universitário é o Higher Education Institutions and Responsible Research and Innovation (Heirri), criado em 2015, a partir de um financiamento de 1,5 milhão de euros da União Europeia, e duração de três anos. O intuito é alinhar pesquisa e inovação de instituições de Ensino Superior com necessidades, valores e iniciativas da sociedade, tendo como respeito os aspectos-chave defendidos pela PIR.

Assim, objetiva levar, para as salas de aula de ambientes universitários e, portanto, aos futuros cientistas, os seis preceitos da PIR, abordando sua importância e refletindo sobre formas de colocá-los em prática nos projetos com os próprios alunos (CORDIS, 2018). Trata-se, portanto, da inovação da prática nas universidades, nas pesquisas e junto às agências de fomento, levando em conta suas responsabilidades para com as comunidades.

A iniciativa, portanto, traz tentativas práticas de implantar a IPR nas instituições de pesquisa, com fomento ao acesso aberto de dados científicos, 
bem como idas a escolas, museus e centros de ciência, como forma de disseminar o conhecimento científico e disponibilizá-lo ao público (CORDIS, 2018; PESQUISA FAPESP, 2017).

O Heirri está ancorado na Community Research and Development Information Service (Cordis) e sua plataforma virtual colaborativa reúne os resultados dos projetos, tornando-os públicos e assim fomentando, principalmente, o acesso aberto à ciência (CORDIS, 2018). Trata-se de uma ferramenta dinâmica, que realiza a disseminação dessas iniciativas de maneira interativa, disponibilizando textos e material em formato multimídia (foto e vídeo). A iniciativa também fomenta o engajamento público da ciência, com a interação entre universidade e sociedade, e, também, de educação científica, tendo em vista que um de seus objetivos é integrar a PIR ao currículo acadêmico (PESQUISA FAPESP, 2017).

Uma das metas do Heirri é promover a internacionalização, estendendo o projeto para além da Europa, de modo a divulgar as propostas da PIR em reuniões científicas internacionais, com o compartilhamento de conceitos e experiências, além da elaboração de materiais didáticos, que poderão ser utilizados para o ensino de graduação e pós-graduação (PESQUISA FAPESP, 2017).

Apesar de ser uma iniciativa importante no âmbito da PIR, o Heirri foca em ações que envolvem prioritariamente as universidades. O fato de a PIR inserir os mais diversos públicos e, sobretudo, pessoas envolvidas em várias áreas sugere que existam distintos pontos de vista e expertises reunidos em determinado tema, o que gera ganho e traz legitimidade e efetividade - e consequente responsabilidade - para possíveis soluções. Mas é necessário atentar para os diferentes níveis de poder e prioridades, aspecto enfocado na próxima seção.

\section{Desafios para implantação da Pesquisa e Inovação Responsáveis no Brasil}

Existem diversos desafios para a aplicação da PIR no Brasil. O principal diz respeito a sua realidade. Por ser um país em desenvolvimento, possui características distintas de países da União Europeia, local no qual o conceito foi originalmente criado e difundido. Além disso, cada uma de suas cinco regiões - 
Centro-Oeste, Nordeste, Norte, Sudeste e Sul - apresenta peculiaridades e diferentes realidades no que diz respeito ao desenvolvimento científico, sendo, portanto, um grande desafio aplicar, à risca, um conceito fechado de PIR.

O desenvolvimento da ciência é produzido, no País, principalmente em universidades, instituições de pesquisa, parques tecnológicos e incubadoras de base tecnológica - estes dois últimos, comumente ligados a universidades. De acordo com dados do último Ranking Universitário da Folha de S. Paulo - RUF (2019), as melhores universidades do País se concentram nas regiões Sudeste e Sul e são públicas - estão nestas duas regiões as oito primeiras mais bem posicionadas, seguidas, em nono lugar, de universidade em Brasília (DF). A ferramenta avalia, anualmente, relacionados a cinco aspectos de todas as universidades ativas - públicas e privadas - no País (no total, 197): pesquisa, ensino, inovação, mercado e internacionalização ${ }^{1}$.

Além destas disparidades, que já dificultam o uso dos conceitos fechados da PIR nas cinco regiões do País, também existe o desafio da aplicação desses conceitos ao compararmos o Brasil com países da Europa.

A PIR “vai ter que ser 'responsável' de formas que não são imediatamente prioritárias para as nações mais desenvolvidas do norte, onde o discurso da IR tem se desenvolvido com mais força”, indicam Macnaghten et al. (2015, p. 20). Seu foco deve "se localizar em um conjunto distinto de debates a respeito do desenvolvimento urbano e econômico, de reformas institucionais, da formação de capacidades, transições e responsabilidade social" (MACNAGHTEN et al., 2015, p. 20).

Segundo Macnaghten et al. (2015), como a PIR nasceu no contexto de países do Norte global, é preciso se atentar ao contexto e premissas embutidas nela, que foi criada de acordo com aquela realidade "em termos culturais, políticos, econômicos, demográficos, de governança e estruturas de poder, de arranjos institucionais e de relações entre ciência e sociedade" (MACNAGHTEN et al., 2015, p.20). No entanto, o conceito se mostra flexível e, no Brasil, é preciso se apropriar dele levando em consideração a sua realidade, para que não se corra o risco de reproduzir ou fortalecer relações de dependência do Sul para com o Norte global. 
De acordo com Broks (2017, p.3, tradução nossa), a PIR "nos obriga a abordar questões fundamentais (...) sobre o papel e objetivo do engajamento do público com eles", o que requer, por sua vez, atenção a contextos locais, regionais e nacionais. "O que acontece se exportarmos a RRI para além da Europa, também temos que exportar esses valores europeus? Não seria uma forma de neocolonialismo? (BROKS, 2017, p.3, tradução nossa).

As questões trazidas por Broks (2017) nos fazem refletir sobre uma possível implementação da PIR em universidades e instituições brasileiras. Por ser um conceito criado e aplicado na Europa, pergunta-se: é possível aplicarmos em um país em desenvolvimento, como o Brasil, com todas as suas dimensões e princípios expostos?

Para isso, é preciso fomentar debates sobre os seis princípios defendidos pela PIR e como se encaixariam na realidade brasileira. No caso da igualdade de gênero, ponderamos duas reflexões importantes: incluir, além da igualdade de gênero, igualdade de raça, especialmente no Brasil, para promover a inclusão social de pessoas negras (pretas ou pardas) e indígenas. Além disso, mais do que pensar sobre o termo "igualdade", considerar a equidade de gênero, para uma análise mais abrangente e coerente (COUTO; GOMES, 2012).

No que diz respeito às políticas públicas, a equidade de gênero traz à tona o conceito de respeito e considera as diferenças, bem como as particularidades de grupos e sujeitos. Assim, pensar em equidade de gênero auxilia em trazer, para debate, homens e mulheres, na luta por direitos e cidadania, levando em conta diferenças que os tornam desiguais, no âmbito da importância social. É uma forma de reconhecer e lidar com as diferenças, por meio da distinção de sujeitos, e trazer ao debate formas de alterar marcos que fundamentam e legitimam essas diferenças no âmbito social (COUTO; GOMES, 2012; GIFFIN, 2002).

Macnaghten et al. (2015) apontam que, no caso específico do Brasil, um foco poderia ser, no âmbito da aplicação da PIR, os biocombustíveis de segunda geração. No entanto, ponderam que seria uma área com baixo impacto na vida cotidiana dos brasileiros, que possuem questões mais urgentes. Nesta direção, os 
autores sugerem engajar a PIR em contextos, culturas e práticas locais, iniciando os debates de acordo com outras realidades:

\begin{abstract}
Ainda que a IR tenha se desenvolvido no contexto de, e como resposta de política pública a, formas controversas ou questionáveis de inovação tecnológica, há que se reconhecer a variedade enorme de inovações sociais que ocorrem no Sul global, direcionadas especificamente para objetivos sociais e/ou ambientais. (MACNAGHTEN et al., 2015, p.21).
\end{abstract}

Um acordo de colaboração no âmbito do programa Horizon 2020 no Brasil viabilizou um projeto envolvendo a Fundação de Amparo à Pesquisa do Estado de São Paulo (FAPESP) e a Universidade Estadual de Campinas (Unicamp), no qual os pesquisadores fomentaram diálogos e debates com diversos agentes para pensar na aplicabilidade do conceito. A iniciativa, intitulada RRI-Practice, estimulou a colaboração entre pesquisadores da Europa e do Estado de São Paulo, com acesso a dados de pesquisa e conexões com redes científicas mundiais. Além do Brasil, participam dessa iniciativa outros sete países da Europa (Noruega, Alemanha, Reino Unido, França, Itália, Bulgária, Holanda), além de Estados Unidos, China, Índia e Austrália (REYESGALINDO; MONTEIRO, 2018).

O projeto estimulou a colaboração entre pesquisadores da Europa e do Estado de São Paulo, com acesso a dados de pesquisa e conexões com redes científicas mundiais. A FAPESP (2021) apoiou projetos conjuntamente submetidos por pesquisadores brasileiros e europeus no âmbito do Horizon 2020, de acordo com as exigências do programa europeu - e, inclusive, possui, em seu site, uma página dedicada aos projetos colaborativos da agência de fomento com o Horizon 2020, com o histórico de todas as chamadas até o momento, mas o Brasil ainda se ressente da dificuldade de desenvolver políticas mais amplas, o que merece atenção - algo também pontuado por Macnaghten et al. (2015, p.24), considerando que "teorias e práticas de IR têm a desafortunada tendência de se separarem, ao passo que é evidente que ambas devem e podem informar umas às outras".

Em matéria publicada pela Pesquisa Fapesp (2017), Marko Monteiro esclareceu que a realidade da ciência brasileira é outra, em relação a de países europeus - nestes últimos, há discussão ampla e institucionalizada relacionada a 
sua integração com a sociedade. No Brasil, ciência e sociedade são vistas, ainda, de forma bastante separada (PESQUISA FAPESP, 2017). Por isso, um caminho para integrar ciência e comunidade consiste em iniciar e fortalecer o diálogo relacionado à PIR.

O Sumário para formuladores de política, produzido no contexto brasileiro, sintetiza os principais pontos da PIR e de um workshop realizado com o apoio da Unicamp para discussão dessa temática no Brasil, que contou com atores-chave no campo da pesquisa e inovação no País. (RESPONSIBLE RESEARCH AND INNOVATION IN PRACTICE, 2018).

"O projeto demonstra que no Brasil há pouco conhecimento sobre o quadro teórico da PIR formulado na Europa, mas há muitas práticas locais que estão alinhadas com os valores promovidos por esse conjunto de políticas" (REYESGALINDO; MONTEIRO, 2018). Os participantes demonstraram interesse em ampliar debates entre instituições de pesquisa e sociedade, por meio de aprimoramento das práticas de comunicação e do engajamento público.

Além disso, o relatório intitulado Report from national case study, publicado em 2018, apontou que ambas as instituições públicas de pesquisa, Unicamp e FAPESP, já possuem missões alinhadas com os princípios da PIR. Foi constatado que não há uma política clara no âmbito da PIR, mas já existem, em ambas as instituições, iniciativas e projetos condizentes com as suas diretrizes, que são relatadas no Report from national case study e estão citadas no Quadro 1. (REYES-GALINDO; MONTEIRO, 2018). 
Quadro 1 - Exemplos de iniciativas relacionadas à PIR na Unicamp e na FAPESP, instituições brasileiras participantes do projeto RRI-Pratice ${ }^{2}$

\begin{tabular}{|c|c|c|}
\hline \multirow[b]{2}{*}{ Preceitos da PIR } & \multicolumn{2}{|c|}{ Instituição brasileira } \\
\hline & Unicamp & FAPESP \\
\hline Governança & Código de governança interno & $\begin{array}{c}\text { Sistema de governança interna, composto por Conselho } \\
\text { Superior e Conselho Técnico-Administrativo }\end{array}$ \\
\hline Ética & Comitês de Ética em Pesquisa & Código de Boas Práticas Científicas \\
\hline Acesso aberto & $\begin{array}{l}\text { Repositório da Produção Científica e } \\
\text { Intelectual Biblioteca Digital Zika }\end{array}$ & $\begin{array}{l}\text { Apoio ao Scientific Electronic Library Online } \\
\text { (SCiELO) }\end{array}$ \\
\hline Igualdade de gênero & $\begin{array}{l}\text { No quesito igualdade social, tem-se } \\
\text { aprovação de cotas raciais }\end{array}$ & Aumento de bolsas a mulheres \\
\hline Educação científica & $\begin{array}{c}\text { Unicamp de Portas Abertas } \\
\text { Feiras de ciências } \\
\text { Conferências, eventos, programas } \\
\text { culturais } \\
\text { Museus de ciências } \\
\text { Cursinhos gratuitos para ingresso na } \\
\text { universidade } \\
\text { Curso interdisciplinar pré-universitário }\end{array}$ & $\begin{array}{c}\text { Centros de Pesquisa, Inovação e Difusão (Cepids) } \\
\text { Conservação e Uso Sustentável da Biodiversidade do } \\
\text { Estado de São Paulo (Biota) } \\
\text { Research, Innovation and Dissemination Centers } \\
\text { (RIDCs) } \\
\text { Financiamento de pesquisas relacionadas à própria } \\
\text { educação, e } \\
\text { iniciativas de educação e pesquisa } \\
\text { Bolsas de estudo e Instituições de Ensino Superior } \\
\text { (IES) } \\
\text { Programa de Pesquisas em Caracterização, } \\
\text { Projeto Mídia e Ciência } \\
\text { Public School Teaching Program }\end{array}$ \\
\hline $\begin{array}{l}\text { Engajamento público } \\
\text { da ciência }\end{array}$ & $\begin{array}{l}\text { Aprovação de cotas raciais } \\
\text { Laboratório de Estudos Avançados em } \\
\text { Jornalismo (Labjor) } \\
\text { Centro Structural Genomics } \\
\text { Consortium - desenvolvimento de } \\
\text { resultados práticos em conjunto com a } \\
\text { indústria farmacêutica }\end{array}$ & $\begin{array}{c}\text { Cepids } \\
\text { Biota } \\
\text { RIDCs } \\
\text { Programa FAPESP de Pesquisa em Bioenergia (Bioen) } \\
\text { Pesquisa Inovativa em Pequenas Empresas (Pipe) } \\
\text { Programa de Apoio à Pesquisa em Parceria para } \\
\text { Inovação Tecnológica (Pite) } \\
\text { Revista Pesquisa FAPESP } \\
\text { Canal para envio de sugestões, reclamações }\end{array}$ \\
\hline
\end{tabular}

Fonte: Elaborado pelos autores.

O Quadro 1 evidencia algumas das ações mapeadas pela Unicamp e pela FAPESP que estão relacionadas à PIR. A síntese dessas iniciativas aqui expostas não tem o intuito de trazer uma investigação detalhada dos princípios e procedimentos da PIR nessas instituições, pois entende-se que essas ações ainda não constituem, exatamente, políticas consolidadas, mas pode servir como um mapeamento inicial para fomentar o tema no Brasil, algo necessário, como justamente defendido por este artigo.

Como boas práticas que se relacionam com a responsabilidade na pesquisa, há destaque ao portal Scientific Electronic Library Online - SCiELO (2021), que permite acesso gratuito à grande parte da produção de pesquisa 
científica no Brasil, algo que não é comumente visto em outros países, inclusive europeus, que geralmente possuem plataformas pagas para o acesso às pesquisas. Além disso, foram apontadas e discutidas algumas das barreiras para aplicação da PIR no Brasil:

[...] resistência a práticas e conceitos vindos do exterior, que possam ser percebidos como interferindo na autonomia institucional e dos pesquisadores; há resistência ainda a pressões em um contexto de insegurança orçamentária e ausência de financiamento sustentável e estável no longo prazo (REYES-GALINDO; MONTEIRO, 2018).

Já uma iniciativa ancorada especificamente pelo Heirri no Brasil - que possui, por enquanto, ações pontuais no País, ocorreu na região Sul do País, com a realização do Seminário "Facilitating reflection on Responsible Research and Innovation", em 2018, que teve a participação de Gema Revuelta, coordenadora do Heirri e diretora do Studies Centre on Science, Communication and Society, da Universidade Pompeu Fabra, da Espanha. O workshop, que ocorreu na Universidade Federal do Rio Grande do Sul - UFRGS (2018), teve a participação de pesquisadores, docentes e demais membros da comunidade acadêmica interessadas na temática e foi organizado pela Association of Public Universities of Catalonia (ACUP) e pela Global University Network for Innovation (GUNi), parceiras do projeto Heirri.

As iniciativas ocorridas no Brasil configuram o início de um debate relacionado à PIR no país. Importante ressaltar a importância de alinhar os preceitos da PIR defendidos na União Europeia à realidade do Brasil e respeitar suas especificidades, o que ainda se configura como um desafio às instituições que necessita de debates e envolvimento de pessoas de diversas áreas e realidades.

\section{Considerações finais}

$\mathrm{O}$ artigo indicou a atual incipiência em pesquisas sobre PIR no Brasil por meio de busca em bases de dados sobre o termo e, ao mesmo tempo, a importância de fomentar o debate em torno da temática para se fazer ciência de forma mais participativa, colaborativa, responsável e crítica, com o engajamento dos mais diversos agentes para a construção de uma sociedade mais sustentável, engajada e cautelosa com o futuro. 
Apesar dos desafios apontados para a implementação da PIR, principalmente devido às particularidades de cada instituição de determinados países, se torna plausível a aplicação da Pesquisa e Inovação Responsáveis em projetos, como tem feito o Brasil e demais países no âmbito do Horizon 2020 e, mais especificamente, pelo Heirri, que consiste em colocar em prática os seis conceitos-chave (governança, educação científica, ética, igualdade de gênero - e raça, de acordo com o entendimento neste artigo -, acesso aberto e engajamento público da ciência), trazendo a inovação, na prática, para universidades, pesquisas e agências financiadoras, de modo que tenha como direcionamento as responsabilidades para com a sociedade.

No entanto, ainda se fazem necessários - e urgentes - amplos debates e estudos sobre o tema, para que, além de disseminar o conhecimento sobre ele, haja a aplicação para possível avaliação de resultados futuros.

As pesquisas sugerem que estes debates devem ser realizados nos mais diversos locais e com os vários agentes para que, assim, tente se chegar, de fato, à real aplicação de uma Pesquisa e Inovação Responsáveis, que seja condizente com as características e políticas de cada local. Ou seja, analisar se, com base nos princípios e premissas defendidos pela Comissão Europeia - e, portanto, inevitavelmente para o contexto específico vivido em países da Europa -, é possível afirmar que estamos, de alguma maneira, produzindo inovação e pesquisa responsáveis - e como aplicá-la em outras áreas e vertentes. Talvez este tema seja, ainda, incipiente e exija mais diálogos e aplicações para que se entenda, na prática, como de fato haveria formas de se saber - e medir - a responsabilidade na ciência.

Por fim, considera-se pertinente adequar princípios e premissas de acordo com a realidade de cada país, levando em consideração seus contextos e suas características particulares, como é o caso do Brasil, que concentra as melhores universidades do País, segundo o RUF (2019), nas regiões Sul e Sudeste, demonstrando desigualdades e peculiaridades em cada região.

Nesse sentido, questiona-se: de quais maneiras seria possível aplicar os princípios da PIR - que se mostram adequados para uma ciência mais participativa -, em instituições brasileiras, levando em consideração as suas 
particularidades e burocracias? Como falar de uma ciência mais responsável e participativa em um País que enfrenta, atualmente, severos cortes de verbas na pesquisa científica? De quais maneiras seria possível ter o apoio governamental e das próprias instituições de pesquisa, universidades, parques tecnológicos e incubadoras tecnológicas para a real implantação da PIR? E como atrelar teoria e prática e, assim, envolver os mais diversos agentes da sociedade pesquisadores, legisladores, políticos, educadores, empreendedores e cidadãos no processo de produção científica? Quais são as lições da primeira década de vigência da PIR no âmbito da União Europeia, que sinalizam a continuidade de seus princípios no próximo programa de pesquisa que deverá viger no continente até 2027, e poderiam inspirar práticas equivalentes no Brasil, considerando inclusive as experiências incipientes no País? As demandas trazidas por cenários imprevisíveis podem facilitar a adoção de PIR nas várias partes do globo e também do Brasil?

A busca por respostas e reflexões sobre estas questões se torna essencial, principalmente no que diz respeito ao engajamento dos mais diferentes agentes, que poderão contribuir para o enriquecimento do diálogo e aplicações da Pesquisa e Inovação Responsáveis na formulação participativa de políticas públicas de ciência e tecnologia.

\section{Referências}

ANGELAKI, Marina. An Introduction to Responsible Research and Innovation. Pasteur 40A. [S. 1.], 2016. Disponível em:

http://pasteur4oa.eu/sites/pasteur4oa/files/resource/RRI_POLICY\%20BRIEF.pd f. Acesso em: 15 jul 2021.

BROKS, Peter. Science communication: process, power and politics. Journal of Science Communication, [S. 1.], v. 16, n. 4, 2017.

CORDIS. COMMUNITY RESEARCH AND DEVELOPMENT INFORMATION SERVICE. 2018. Heirri (Higher Education Institutions and Responsible Research and Innovation). Disponível em: https://cordis.europa.eu/project/id/666004. Acesso em: 10 maio 2021.

COUTO, Marcia Thereza; GOMES, Romeu. Homens, saúde e políticas públicas: a equidade de gênero em questão. Ciência \& Saúde Coletiva, [S. 1.], v. 17, n. 10, p. 2569-2578, 2012. 
EUROPEAN COMISSION. Horizon 2020 Framework Programme: Science with and for Society. European Comission: 2020a. Disponível em: https://ec.europa.eu/programmes/horizon2020/en/h2020-section/science-andsociety. Acesso em: 10 mar 2020.

EUROPEAN COMISSION. Implementation strategy for Horizon Europe: Version 1.0. European Comission: 2020b. Disponível em: https://ec.europa.eu/info/sites/default/files/research_and_innovation/strategy_on _research_and_innovation/documents/ec_rtd_implementation-strategy_he.pdf. Acesso em: 24 jun 2020.

FAPESP. FUNDAÇÃO DE AMPARO À PESQUISA DO ESTADO DE SÃO PAULO. 2021. Convênios e acordos de cooperação. Disponível em: https://fapesp.br/acordos-h2020. Acesso em: 5 mar 2021.

GIFFIN, Karen. Pobreza, desigualdade e eqüidade em saúde: considerações a partir de uma perspectiva de gênero transversal. Cadernos de Saúde Pública, Rio de Janeiro, n.18 (Supl.), p. 103-112, 2002.

HARTLEY, Sarah; PEARCE, Warren; TAYLOR, Alasdair. Against the tide of depoliticisation: the politics of research governance. Policy \& Politics, [S. 1.], v. 45, n. 3, p. 361-377, 2017.

HEIRRI. HIGHER EDUCATION INSTITUTIONS AND RESPONSIBLE RESEARCH AND INNOVATION. 2015. Disponível em: https://heirri.eu/. Acesso em 10 maio 2021.

KOWALSKI, Raquel Pasternak Glitz. Metodologia de projeto para o ensino de design: uma proposta de aprendizagem colaborativa na perspectiva da pesquisa e inovação responsáveis. Tese (Doutorado em Educação). Curitiba, PR: Pontifícia Universidade Católica do Paraná, 2018.

MACNAGHTEN, Phil et al. Inovação responsável através de fronteiras: tensões, paradoxos e possibilidades. Teoria \& Pesquisa, [S. 1.], v. 24, n. 2, p. 18-24, 2015.

MACNAGHTEN, Phil; SYKES, Kathy. Responsible Innovation - Opening Up Dialog and Debate. In: OWEN, Richard; BESSANT, John. (ed.). Responsible Innovation: Managing the Responsible Emergence of Science and Innovation in Society. [S.1.]: John Wiley \& Sons, Ltd., 2013. p. 85-108.

NICOLESCU, Basarab. Um novo tipo de conhecimento - transdisicplinaridade. In: Encontro Catalisador do CETRANS - Escola do Futuro, 1., 1999, Itatiba: USP, 1999. p. 1-10.

PESQUISA FAPESP. Inovação Responsável na UE. Pesquisa FAPESP. São Paulo, n. 252, p. 8-10, 2017. 
POSTAL, Andreia Marques; RIBEIRO, Carolina Habib; BENATTI, Gabriela Solidario de Souza. Inovação responsável como ferramenta teórica para avaliação de iniciativas voltadas à produção de biocombustíveis. In: CONGRESSO SOBER - SOCIEDADE BRASILEIRA DE ECONOMIA, ADMINISTRAÇÃO E SOCIOLOGIA RURAL, 57., 2019, Ilhéus. Anais [...]. Uesc, 2019.

RANKING UNIVERSITÁRIO FOLHA - RUF. 2019. Disponível em: ruf.folha.uol.com.br. Acesso em 5 mar. 2021.

RESPONSIBLE RESEARCH AND INNOVATION IN PRACTICE. 2016. Disponível em: https://www.rri-practice.eu/. Acesso em: 5 mar 2021.

RESPONSIBLE RESEARCH AND INNOVATION IN PRACTICE. Sumário para formuladores de política. 2018.

REYES-GALINDO, Luis; MONTEIRO, Marko. Report from national case study - Brazil. Responsible Research and Innovation in Practice. 2018.

RRI TOOLS. [Website]. 2021. Disponível em: https://rri-tools.eu/. Acesso em: 2 mar 2021.

SCHOLTEN, Victor et al. Science communication and Responsible Research and Innovation. How can they complement each other? Journal of Science Communication, [S. 1.], v. 15, n. 06, 2016.

SCIELO. SCIENTIFIC ELECTRONIC LIBRARY ONLINE. [2021]. Disponível em: https://scielo.org/. Acesso em: 5 mar 2021.

STILGOE, Jack; OWEN, Richard; MACNAGHTEN, Phil. Developing a framework for responsible innovation. Research Policy, [S. 1.], v. 42, n. 9, p. 1568-1580, 2013.

TORRES, Patricia Lupion; KOWALSKI, Raquel Pasternak Glitz; SANTOS, Katia Ethiénne Esteves. RRI: Uma experiência de decisões conscientes no desafio da cibercultura. Educação em Foco, [S. 1.], v. 23, n. 1, p. 175-200, 2018.

UFRGS. UNIVERSIDADE FEDERAL DO RIO GRANDE DO SUL. HEIRRI workshop in Brasil: Facilitating reflection on responsible research and innovation. 2018. Disponível em:

http://www.ufrgs.br/inov/divulgacao/eventos/heirri-workshop-in-brasilfacilitating-reflection-on-responsible-research-and-innovation. Acesso em: 4 maio 2021.

VON SCHOMBERG, Rene (ed.). Towards responsible research and innovation in the information and communication technologies and security technologies fields. Luxembourg: Publications Office Of The European Union, 
2011. Disponível em:

https://papers.ssrn.com/sol3/papers.cfm?abstract_id=2436399. Acesso em: 3 maio 2020.

\title{
Responsible Research and Innovation: conception, emergence and challenges for implementation
}

\begin{abstract}
Currently, there is a demand to produce science in a participatory way, since agents of society - researchers, legislators, politicians, educators, entrepreneurs and citizens - must be involved in the scientific production process (from the construction of the agenda to the completion of the project and results) in order to foster the construction of a responsible society with the future. The challenges arising from this context have been object of theoretical approaches to Research and Responsible Innovation, which article describes, examines and contextualizes in the current scenario. The methodology includes bibliometric and bibliographic reviews, used in order to understand the dissemination of the term in the English and Portuguese (Brazil) languages, in addition to rescuing the context of the RRI, exploring its concepts and principles. We sought to reflect on the challenges of implementing RRI in Brazil. It is expected to contribute to the RRI dialogue in the country and to raise reflections on the importance of applying it to agents and initiatives responsible for the socioeconomic and environmental spheres.
\end{abstract}

Keywords: Responsible Research and Innovation; Public engagement with science; Science, Technology and Innovation; Science, Technology and Society; Public policy

Recebido: $24 / 03 / 2021$

Aceito: 02/06/2021

\section{Declaração de autoria}

Concepção e elaboração do estudo: Maria Zanin, Adriana Gonçalves Arruda, Danilo Rothberg.

Coleta de dados: : Maria Zanin, Adriana Gonçalves Arruda, Danilo Rothberg. Análise e interpretação de dados: Maria Zanin, Adriana Gonçalves Arruda, Danilo Rothberg.

Redação: Maria Zanin, Adriana Gonçalves Arruda, Danilo Rothberg.

Revisão crítica do manuscrito: Maria Zanin, Adriana Gonçalves Arruda, Danilo Rothberg.

\section{Como citar:}

ZANIN, Maria; ARRUDA, Adriana Gonçalves; ROTHBERG, Danilo. Inovação e pesquisa responsável: conceituação, surgimento e desafios para implementação. Em Questão, Porto Alegre, v. 27, n. 4, p 14-38. 2021. Doi: http://dx.doi.org/10.19132/1808-5245274.14-38 
Pesquisa e inovação responsáveis: conceituação,

surgimento e desafios para implementação

Maria Zanin, Adriana Gonçalves Arruda, Danilo Rothberg

${ }^{1}$ Dados detalhados sobre o processo de produção do Ranking Universitário da Folha (RUF), como etapas e metodologia, podem ser consultados em seu site (ruf.folha.uol.com.br).

${ }^{2}$ Detalhes sobre todas as iniciativas citadas podem ser consultados nos sites das instituições Unicamp (unicamp.br) e FAPESP (fapesp.br). O objetivo do Quadro 1 foi apenas exemplificar as ações relacionadas à IPR, sem o intuito de detalhá-las. 